\title{
A Meritocracia e a Reprodução da Desigualdade: análise comparativa entre trajetórias SOCIAIS DE AGENTES DO CAMPO JURÍDICO ${ }^{1}$
}

Mariana Garcia²

\section{INTRODUÇÃO}

Este texto resume alguns resultados de pesquisa que almejam comparar trajetórias sociais de bacharéis em direito pertencentes a classes e frações de classe distintas, com o intuito de examinar as formas de reprodução de desigualdades ocupacionais no interior do campo jurídico. Trata-se de investigar os fundamentos sociais do secular recrutamento elitista do Poder Judiciário, cuja forma de seleçáo beneficia amplamente os setores privilegiados da sociedade brasileira, que acabam por monopolizar os cargos mais cobiçados e rentáveis da burocracia estatal.

Esse recrutamento, que outrora ocorria pela reprodução familiar, hoje se legitima por meio da justificativa meritocrática. De um lado, identificam-se agentes da classe média e média alta, herdeiros de um volumoso capital econômico, cultural e social - que, inicialmente, conseguem ocupar as vagas das universidades mais prestigiadas e, na sequência, os cargos mais cobiçados do Poder Judiciário ou da advocacia privada. De outro lado, agentes originários de famílias da fraçáo superior da classe trabalhadora, sejam entendidos como batalhadores ou nova classe trabalhadora, que percorrem uma trajetória de escolaridade superior menos prestigiosa e vem ocupar posiçóes consideradas subordinadas no campo jurídico. ${ }^{3}$ Esses novos trabalhadores do direito fazem parte da geração de brasileiros que passou a ingressar no ensino superior com a recente ampliaçáo do acesso à universidade, tendo sido beneficiários tanto de políticas públicas inclusivas - como o Programa Universidade para Todos (ProUni) e o Fundo de Financiamento Estudantil (FIES) - quanto do aumento das vagas em universidades públicas e das cotas.

\section{METODOLOGIA}

Este texto investiga os fundamentos sociais do sucesso na luta pelos recursos estatais, especificamente no que toca ao acesso ao Judiciário, e, ao mesmo tempo, busca entender a lógica social que condiciona a reprodução das desigualdades no campo jurídico. Além disso, pretende contribuir para compreender as potencialidades, limitações e ambivalências das políticas de inclusão universitária dos jovens brasileiros e demonstrar como se dá o processo de reprodução das desigualdades sociais entre agentes que adquirem o mesmo capital cultural objetivado via diploma universitário.

O material empírico utilizado para este estudo é fruto da participação na pesquisa Radiografia do Brasil Contemporâneo, realizada pelo Ipea entre 2015 e 2016, que teve como objetivo central "o mapeamento geral das classes sociais e seus ambientes, bem como a reconstrução crítica das inclinaçóes práticas que as compóem" (Ipea, 2016a). Naquela oportunidade foi desenvolvida uma pesquisa qualitativa

1. DOl: http://dx.doi.org/10.38116/bapi23art7

2. Pesquisadora do Programa de Pesquisa para o Desenvolvimento Nacional (PNPD) na Diretoria de Estudos e Políticas do Estado, das Instituições e da Democracia (Diest) do Ipea.

3. Para este estudo, utilizamos a definição de Bourdieu (2011, p. 212) que compreende que o "campo jurídico é o lugar de concorrência pelo monopólio do direito de dizer o direito, quer dizer, a boa distribuição (nomos) ou a boa ordem, na qual se defrontam agentes investidos de competência ao mesmo tempo social e técnica que consiste essencialmente em interpretar (de maneira mais ou menos livre ou autorizada) um corpus de textos que consagram a visão legítima, justa, do mundo social". 
que abarcou 632 entrevistas em profundidade, multitemáticas e de abrangência nacional visando ao "exame de narrativas individuais de acordo com esquemas objetivos de socialização” (Ipea, 2016b). As entrevistas foram acompanhadas por um questionário socioeconômico, com pessoas de várias classes sociais, moradores de áreas urbanas de todas as macrorregiōes do país. A abordagem teórico-metodológica que embasou o estudo prezou pela captura das diversas dimensóes que compóem a vida e a trajetória social dos agentes. $\mathrm{Na}$ esteira dessa expectativa, a pesquisa permitiu o estudo combinado de narrativas individuais e processos objetivos de socialização, abarcando os principais fatores responsáveis por demarcar padróes comportamentais semelhantes, bem como a reconstrução compreensiva das inclinaçóes e dos seus contextos de produção e reprodução. Por fim, cabe salientar que a pesquisa Radiografia do Brasil Contemporâneo abordou três eixos temáticos principais: i) a relaçáo entre socialização familiar e desempenho escolar; ii) a consequente inserção no mercado de trabalho; e iii) as variaçóes em função da origem de classe.

Inicialmente, realizamos a análise de todas as entrevistas dos 45 agentes do campo jurídico coletadas na pesquisa, em busca de regularidades e pontos relevantes de comparação entre as trajetórias sociais. Na sequência, selecionamos as entrevistas de agentes dos dois polos do campo que nos interessaram primordialmente: as narrativas dos agentes da elite do campo jurídico, especificamente daqueles que ocupam as posiçóes mais rentáveis econômica e simbolicamente; e as narrativas de agentes da fração de classe dos assim chamados batalhadores (Souza, 2010), que ocupavam posiçóes subalternas no campo e, sobretudo, alcançaram o diploma de bacharel em razão dos programas de financiamento estudantil. Selecionamos, portanto, entrevistas de agentes que apresentaram trajetórias típicas em um dos polos, excluindo as entrevistas de agentes que ocupavam posiçóes médias no campo. Finalmente, realizamos a análise qualitativa nas entrevistas selecionadas, tendo como foco a comparação entre os relatos no que toca à dimensão da formação universitária, do aprendizado da profissão e da transição entre a escola e o trabalho.

\section{DISPUTA E ACESSO AOS RECURSOS ESTATAIS}

No campo jurídico, encontram-se agentes de diferentes classes sociais, que mobilizam distintas estratégias na disputa por recursos escassos, tanto na tentativa de angariar clientes quanto na de ingressar em carreiras da burocracia do Judiciário. O acesso aos cargos mais rentáveis e de maior prestígio das instituiçóes do campo jurídico é disputado por agentes que possuem determinadas precondições, ligadas à condição de classe. A partir de trajetórias sociais específicas, é possível entender os fundamentos sociais do acesso às ocupaçóes estatais que possuem maior renda total na média das declaraçóes de Imposto de Renda: titular de cartório; procurador ou promotor do Ministério Público; e juiz (Souza, 2016). Não obstante o grande número de agentes da nova classe trabalhadora que ingressou no campo jurídico, o núcleo dos cargos estatais mais rentáveis segue sendo disputado por agentes específicos, pertencentes aos estratos dominantes da sociedade brasileira. Tudo isso gera alguns questionamentos. Afinal, o acesso aos cargos públicos não está disponível a todos? Não depende apenas do esforço pessoal? Como se dá a disputa no campo jurídico? Quais os fundamentos sociais do recrutamento das instituições jurídicas?

Partimos, aqui também, das noções de Pierre Bourdieu acerca do Estado e sobre as relações entre o campo político, administrativo (burocrático) e jurídico. Para o autor francês, o Estado é uma fonte de recursos materiais e simbólicos, em torno do qual ocorre uma luta contínua, travada por agentes interessados no acesso e no controle desses recursos. A tradicional separação entre Estado e sociedade civil é substituída pela "ideia de um continuum que é uma distribuição contínua do acesso aos recursos coletivos, públicos, materiais ou simbólicos, aos quais se associa o nome 'Estado”, e "essa distribuição seria, 
como todas as distribuiçốes em todos os universos sociais, fundamento e objeto de lutas permanentes" (Bourdieu, 2014, p. 70). Em suma, o acesso privilegiado aos recursos estatais confere a determinados agentes vantagens econômicas e simbólicas: garante os desejados salários e demais benefícios que são pagos às funçóes do primeiro escalão estatal; e assegura, também, a possibilidade de falar em nome do Estado, em nome do universal, do oficial, quer dizer, de exercer o poder simbólico acumulado ao longo do processo de construção do Estado e perpetuado por meio de uma socialização de classe específica.

\section{TRAJETÓRIAS SOCIAIS}

Como se dá o acesso aos cargos públicos? Qual a relação das classes sociais com os recursos estatais? No que toca ao Poder Executivo e ao Poder Legislativo, temos acompanhado a construção de um relativo consenso no sentido da constatação de que o poder econômico necessário para se eleger, por meio do voto, os representantes políticos constitui um desafio à democracia, pois acabam eleitos apenas aqueles que conseguiram mobilizar vultosas quantias, doadas por grandes corporaçóes, que posteriormente cobram dos representantes políticos a defesa de seus próprios interesses ou das corporaçóes que representam (Cervi et al., 2015). A outra forma de acesso aos cargos dos poderes estatais, que em tese não padeceria desses problemas, é aquela que se dá por meio de concurso público, forma utilizada por excelência no Poder Judiciário. O concurso, nessa perspectiva, teria por função garantir a justiça do recrutamento estatal, fundada na ideia de meritocracia. Será que é possível concordar com essa narrativa de legitimação?

É que o sucesso ou o fracasso nas disputas em questão vai depender de variáveis na trajetória social, que influenciarão decisivamente a posição que certo agente ocupará nesse campo. A preparação para os concursos mais cobiçados exige precondiçôes bem definidas, que só estão disponíveis, em regra, aos agentes da alta classe média. É dessa forma que conseguem acessar os recursos materiais e simbólicos disponíveis no contexto do Poder Judiciário, fato que é legitimado pela narrativa da meritocracia, que produz a ilusão de que, diante dos concursos públicos, tais cargos estão disponíveis para todos, independentemente da condição de classe, e que são recrutados apenas os mais "preparados", "dedicados" ou "talentosos".

A avaliação do material empírico permite notar que os agentes da classe média estudaram em escolas privadas e, em geral, acessaram a universidade pública, ao passo que os agentes da classe dos batalhadores estudaram em escolas públicas e acessaram, em geral, a universidade privada. Enquanto os agentes da classe média puderam fazer estágios voluntários ("pagar para trabalhar"), os batalhadores necessitaram trabalhar, em diversos tipos de empregos, para pagar a mensalidade ou o financiamento que lhes garantiria o pagamento da mensalidade da universidade privada. Com isso, a rotina desses agentes é bastante diferente (mais ou menos tempo de estudo, uso de carro próprio ou transporte público etc.), o que pode ser relevante no destino social de cada um.

O acesso à universidade - pública ou privada - já será condicionado pela formação escolar e pela rotina durante esse período. Para além das diferenças de qualidade entre as escolas - privadas ou públicas -, encontramos diferentes experiências de escolarização, que têm a ver, principalmente, com o tempo livre, tempo de dedicação exclusiva ou de combinação escola-trabalho. Nas trajetórias dos batalhadores, o início da vida laboral ocorreu ainda durante o ensino médio, entre as idades de 14 e 16 anos. Disso decorre, geralmente, a necessidade de estudar à noite.

Um dos entrevistados é o caçula de quatro irmãos, o único da família que teve acesso ao ensino superior. Começou a trabalhar com 15 anos, como assistente administrativo, quando passou a estudar 
de noite. Depois de concluir o ensino médio, conseguiu um emprego de office boy em um escritório de advocacia, substituindo o seu irmão mais velho que atuava na mesma função. A vontade de fazer uma faculdade já existia e, após algum tempo trabalhando, encantado com o escritório de advocacia, resolveu tentar ingressar no ensino superior. Segundo conta, sequer tentou uma universidade pública. Entrou em uma universidade privada e após um ano pagando a mensalidade, com o auxílio da mãe, obteve o FIES.

Essa foi uma regularidade encontrada. Outro entrevistado começou a trabalhar aos 14 anos, também como office boy de um escritório de advocacia, no qual, hoje, aos 24 anos, recém-formado, é advogado contratado. Seu pai era vendedor de uma loja de roupa masculina e conseguiu o emprego para o filho com um advogado notável que era seu cliente. Aos 16 anos, esse entrevistado passou a trabalhar em turno integral e, consequentemente, a estudar de noite. Por essa razão, e também pela clara percepção de que seu ensino médio havia sido fraco, também sequer tentou ingressar na universidade pública.

A aprovação no concurso público é uma realidade distante para os batalhadores do campo jurídico. Em diversas narrativas os entrevistados manifestaram tal desejo, mas as dificuldades em relação a tempo e dinheiro para fazer os cursinhos preparatórios são fatores que atrapalharam a empreitada.

Alguns entrevistados, no entanto, decidem enfrentar o desafio, de modo que acabam constituindo um mercado importante para os serviços de cursos preparatórios. A própria publicidade dessas instituiçóes capta com precisão a ideologia que rege a condução da vida da classe dos batalhadores. Por um lado, apelam para a promessa de sucesso; ${ }^{4}$ e, por outro, utilizam depoimentos de vencedores, que, em geral, se assemelham a testemunhos pentecostais, preconizando a constante renovação da fé e da ética do trabalho duro. Salvo exceçóes, o trabalhador desse perfil provavelmente não será aprovado em nenhum concurso, pois as estruturas objetivas do cotidiano de alguém que não estuda para trabalhar, mas trabalha para ter a chance de estudar (Souza, 2010, p. 77) dificultam o desenvolvimento das precondiçóes para o sucesso nesse tipo de disputa, por exemplo, a organização de um tempo próprio para o estudo: "é como se as portas do universo escolar se abrissem pela metade ou pelo menos uma pequena fresta pela qual as classes dominadas podem dar uma pequena espiada" (op. cit., p. 79).

Outro ponto relevante diz respeito ao grande número de bacharéis que alcançam o diploma por meio do ensino universitário privado, mas na sequência não conseguem ser aprovados na prova da Ordem dos Advogados do Brasil (OAB), de modo a habilitar-se para o exercício de serviços jurídicos. ${ }^{5}$ Há atualmente um enorme contingente de bacharéis, que constituem uma espécie de "exército de reserva minimamente escolarizado para o trabalho precário" (Souza, 2010, p. 63), e que encontram acomodação profissional nesse tipo de trabalho em grandes escritórios de advocacia. Trata-se de um caso típico do desencontro "entre qualificaçôes e ocupaçóes" (Comin e Barbosa, 2011, p. 76). Os batalhadores do campo jurídico, após investirem tempo e dinheiro na formação acadêmica, podem acabar numa espécie de limbo, porque "por mais que as dinâmicas do mercado de trabalho e do sistema educacional estejam entrelaçadas de muitas maneiras, o curso de cada uma obedece a diferentes lógicas e temporalidades" (idem, ibidem).

4. "O sucesso espera por você" é o slogan de um dos maiores cursinhos do Brasil.

5. Conforme os dados apresentados pelo relatório Exame de Ordem em Números, v. 3, produzido pelo Conselho Federal da Ordem dos Advogados do Brasil e pela unidade de assessoria técnica da Fundação Getulio Vargas, FGV Projetos, em 2016, os examinandos provenientes de instituições de ensino superior privadas responderam por $93 \%$ dos inscritos. A taxa de aprovação média desses examinandos, no entanto, foi de 18\%, ou seja, muito inferior à verificada no tocante às instituições de ensino superior públicas que alcançaram um índice de $40 \%$ de aprovação. 


\section{CONSIDERAÇÕES FINAIS}

A análise das trajetórias dos agentes que chegaram aos cargos mais rentáveis do campo jurídico permite investigarmos de perto as diferenças sutis entre as classes e as fraçóes de classe, que refletem na reprodução das desigualdades. Entre os relatos analisados, não consta nenhum caso no qual o agente tenha começado a trabalhar ainda na época da escola, como é comum no caso dos batalhadores. Os estágios na área de formação são em regra a primeira experiência laboral. O estágio, entretanto, é buscado não por qualquer necessidade financeira - o sustento compete aos pais durante a faculdade e, sim, a partir da ideia de que ele é uma dimensão importante do próprio aprendizado da profissão. Os sujeitos da alta classe média, em suas palavras, "pagam para trabalhar". Fazem estágios voluntários, em busca de aprendizado, pois o sustento é garantido pelos pais, no mínimo, até o final da formação universitária. Ademais, por vezes esses estágios são obtidos por meio de relaçóes pessoais e familiares (capital social).

Esses agentes, portanto, gozam de vantagens na disputa por recursos escassos, isto é, possuem recursos herdados que lhes possibilitam a dedicação exclusiva à formação acadêmica e a busca dos objetivos profissionais, o que pode ser decisivo em suas trajetórias. Além das dádivas que recebem - uma sala para trabalhar, por exemplo, evitando assim que o iniciante na carreira tenha que arcar com aluguel -, os agentes da elite do campo jurídico geralmente possuem também capital social, o que contribui para o bom andamento de suas carreiras, abrindo portas por meio de indicaçóes, contatos etc.

Como dissemos, o recrutamento dos agentes das carreiras jurídicas mais rentáveis ocorre por meio de concursos públicos. As pesquisas empíricas que têm sido realizadas sobre o assunto demonstram que os sujeitos que obtêm sucesso nas disputas pertencem à classe média, sobretudo a partir da análise da renda e das ocupaçóes dos pais (Werneck Vianna et al., 1997). O que nos interessa é estudar quais são as vantagens que a classe média possui e como ela traduz essas vantagens do ponto de vista das estratégias de reprodução dos capitais.

A preparação para os concursos mais disputados exige condições específicas, e a presença dessas condiçôes nos casos de sucesso é uma regularidade descoberta no estudo. O treinamento para as provas que garantem o acesso às ocupaçóes mais rentáveis - econômica e simbolicamente - do campo jurídico exige um intenso esforço, uma rotina específica, que pode se prolongar por anos. O que parece claro é que a própria possibilidade de realizar este esforço depende de pressupostos objetivos relativos à posição de classe do agente.

Para além da socialização primária e das disposições para o sucesso escolar, que posteriormente redundarão no acesso às melhores universidades e a possibilidade de dedicação exclusiva à formação acadêmica pelos agentes da alta classe média, o elemento que se apresenta fundamental durante a corrida pelos concursos públicos é o capital tempo livre, isto é, a chance de colocar em suspenso, por algum tempo, a necessidade de autossustento, por meio do suporte familiar. Em síntese, a possibilidade de se dedicar exclusivamente ao treinamento para as provas, tendo em vista o privilégio de poder abdicar de remuneração laboral. Trata-se de um capital que permite investir num cargo futuro que em princípio é incerto, não está garantido. 


\section{REFERÊNCIAS}

BOURDIEU, P. O poder simbólico. 15. ed. Rio de Janeiro: Bertrand Brasil, 2011.

Letras, 2014.

. Sobre o Estado: cursos no Collège de France (1989-1992). São Paulo: Companhia das

CERVI, E. U. et al. Dinheiro, profissão e partido: a vitória na eleição para deputado federal no Brasil em 2010. Revista Sociedade e Estado, v. 30, n. 1, Brasília, jan./abr., 2015.

COMIN, Á. A.; BARBOSA, R. J. Trabalhar para estudar. Sobre a pertinência da noção de transição escola-trabalho no Brasil. Revista Novos Estudos Cebrap, n. 91, p. 75-95, 2011.

IPEA - INSTITUTO DE PESQUISA ECONÔMICA APLICADA. Radiografia do Brasil Contemporâneo. Brasília: Ipea, 2016a.

Relatório parcial - Radiografia do Brasil Contemporâneo. Brasília: Ipea, 2016b.

SOUZA, J. Os batalhadores brasileiros: nova classe média ou nova classe trabalhadora? Belo Horizonte: Editora UFMG, 2010.

SOUZA, P. H. G. F. de. A desigualdade vista do topo: a concentração de renda entre os ricos no Brasil, 1926-2013. 2016. Tese (Doutorado) - Universidade de Brasília, 2016.

WERNECK VIANNA, L. et al. Corpo e alma da magistratura brasileira. Rio de Janeiro: Revan, 1997.

\section{BIBLIOGRAFIA COMPLEMENTAR}

ADORNO, S. Os aprendizes do poder: o bacharelismo liberal na política brasileira. Rio de Janeiro: Paz e Terra, 1988.

ALMEIDA, F. de. A nobreza togada: as elites jurídicas e a política da justiça no Brasil. 2010. Tese (Doutorado) - Universidade de São Paulo, São Paulo, 2010.

CARVALHO, J. M. de. A construçáo da ordem: a política imperial. Brasília: Editora UnB, 1981.

ENGELMANN, F. Diversificação no espaço jurídico das lutas pela definição do direito no Rio Grande do Sul. 2004. Tese (Doutorado) - Universidade Federal do Rio Grande do Sul, 2004.

SCHWARCZ, L. M. O espetáculo das raças: cientistas, instituições e a questão racial no Brasil 1870-1930. São Paulo: Companhia das Letras, 1993. 